\title{
Long term psychosocial outcomes after mild head injury in early childhood
}

\author{
A McKinlay, J C Dalrymple-Alford, L J Horwood, D M Fergusson
}

J Neurol Neurosurg Psychiatry 2002;73:281-288

See end of article for authors' affiliations

.....................

Correspondence to:

Dr A McKinlay, Department

of Psychology, University of

Canterbury, Private Bag

4800, Christchurch,

New Zealand;

aco24@

student.canterbury.ac.nz

Received

1 October 2001

In revised form 20 May

2002

Accepted 31 May 2002

\begin{abstract}
Objectives: The question of whether any adverse cognitive or psychosocial outcomes occur after mild head injury in early childhood has evoked considerable controversy. This study examined mild head injury before age 10 and potential differences in late childhood/early adolescence as a function of severity of mild injury and age at injury.

Methods: A fully prospective longitudinal design tracked a large birth cohort of children. Confirmed cases of mild head injury before age 10 were divided on the basis of outpatient medical attention $(n=64-84)$ or inpatient observation (hospital overnight; $n=26-28$ ) and compared with the non-injured remainder of the cohort (reference group; $n=613-807$ ). A range of pre-injury and post-injury child and family characteristics were used to control for any potential confounds. Outcome after injury before and after age 5 was also assessed.

Results: After accounting for several demographic, family, and pre-injury characteristics, the inpatient but not the outpatient group displayed increased hyperactivity/inattention and conduct disorder between ages 10 to 13, as rated by both mothers and teachers. Psychosocial deficits were more prevalent in the inpatient subgroup injured before age 5 . No clear effects were evident for various cognitive/academic measures, irrespective of severity of mild injury or age at injury.

Conclusions: Most cases of mild head injury in young children do not produce any adverse effects, but long term problems in psychosocial function are possible in more severe cases, perhaps especially when this event occurs during the preschool years. The view that all mild head injuries in children are benign events requires revision and more objective measures are required to identify cases at risk.
\end{abstract}

t $\mathrm{t}$ is expected that moderate to severe head injury in children will produce negative outcomes on cognitive, academic, and psychosocial variables, ${ }^{1}$ but the idea that similar effects may occur after instances of mild head injury is a controversial one..$^{2-5}$ Mild head injury is usually considered an insignificant event as any alteration in consciousness is transient and medical intervention is rare. Despite growing evidence that mild head injury can be associated with structural abnormalities, including diffuse axonal injury and cortical contusions, ${ }^{6-9}$ any lasting consequence in children is generally regarded as unlikely. Indeed, there is a widespread belief that younger individuals show greater neuroplasticity and accelerated recovery after any brain injury. ${ }^{10}{ }^{11}$ Recent reports that moderate to severe brain injury in early childhood has a more negative outcome than when it occurs in older childhood, however, have renewed speculation that early mild injuries may also have some lasting consequences..$^{1-3}{ }^{12}$ Mild head injury is experienced by a significant number of children. For example, there are about 90000 cases who are hospitalised each year in the US. ${ }^{13}{ }^{14}$ It is therefore important to clarify the impact of these events, especially any long term effects, because they potentially constitute an important health concern.

In recent reviews of mild head injury in children, Satz and colleagues concluded that there may be a weak yet transient change in cognition, but no reliable effects on academic or psychosocial measures. ${ }^{45}$ It is, however, significant that these reviews also highlighted frequent methodological problems in this research area, which adds to uncertainty regarding the influence of these early life events. In fact, barely half of the studies reviewed ( 26 of 56) were methodologically adequate in terms of meeting at least four of the following recommendations. ${ }^{45}$ (1) A clear definition of mild injury without including children with more severe injuries. (2) The inclusion of control groups (no head injury or other injury). (3) Controls for pre-injury risk factors. (4) The use of a longi- tudinal design with follow up assessment after the injury. (5) The use of standardised tests to measure outcomes. And (6) The inclusion of at least 20 children with mild head injury.

Clearly, the evidence on mild head injury in children exhibits many shortcomings. We therefore re-examined the question of potential changes in psychosocial behaviour and academic performance in children who had experienced a mild head injury event in the context of the Christchurch Health and Development Study of over a 1000 children born in mid-1977. This longitudinal epidemiological study fulfilled all six of Satz's recommendations, including a range of pre-injury and post-injury information to control for several potential confounds. In addition, fully prospective information was available on the child and family through interviews conducted on a regular basis since birth. ${ }^{15}{ }^{16}$ This information was free of any injury related bias, because it was collected during interviews that were completely unrelated to any head injury event. Use of a large birth cohort meant that our sample was more representative than is the case with the opportunistic samples commonly used. Furthermore, the non-injured sample was an ideal reference group for comparative purposes because of their unusually similar background to those children who had experienced a head injury.

Even when most of Satz's original recommendations are met, previous studies usually provide little or no longitudinal perspective and often concentrate on injuries in older children or adolescents who will have a range of established cognitive and behavioural skills. The adult pattern of an initial deficit followed by recovery ${ }^{17}$ may not occur in young children who are experiencing a period of more active developmental change. Some evidence already exists that the initial effects of early brain injury may even worsen as they interact with developmental processes and impede the acquisition of new skills. ${ }^{13}{ }^{18}$ Delayed onset of deficits may be especially relevant 
for psychosocial behaviour, because these skills are strongly mediated by the prefrontal cortex, which has a prolonged developmental course. ${ }^{19}$ Interestingly, one of the two studies that met all six of Satz's criteria reported that mild head injury between 5 and 10 years of age was associated with higher teacher, but not higher mothers' ratings of hyperactive/ inattentive behaviour. ${ }^{20}$ For our study, the long term effect of a mild head injury experienced any time before the age of 10 was evaluated when the children were in late childhood to early adolescence. We also examined the consequences of a mild head injury sustained before and after the age of 5, the onset of formal schooling for most children. There is little information on the question of mild head injury in preschool children. One study reported that the timing of mild head injury before or after the age of 5 is irrelevant, ${ }^{21}$ but other work suggests that the early years may indeed be a more susceptible period in terms of mild head injury effects. ${ }^{3}$

The lack of clear mild head injury criteria and the treatment of all cases as a homogeneous category constitute two other important confounds in the literature that may explain some of the mixed findings. One study included any child experiencing a blow to the head, with or without evidence of concussive symptoms. ${ }^{22}$ Conversely, even mild to severe cases have often been collapsed into a single target group (see for example references ${ }^{23-25}$ ). Indeed, the only previous study with follow up data longer than 10 years reported adverse changes in physical, emotional, and intellectual domains, but its findings were based on non-standardised self reports and a sample that included $10 \%$ of moderate or severe cases. ${ }^{26}$ Hence a novel methodological refinement in our study was to divide explicit cases of mild head injury on the basis of whether the injury required outpatient treatment or temporary inpatient care. This division can reasonably be related to the severity of mild injury ${ }^{27}$ and addresses the recent proposal that there may be a degree of mild injury that reaches a threshold of concern. ${ }^{5}$

\section{METHOD \\ Subjects}

The Christchurch Health and Development Longitudinal Study has charted an initial cohort of 1265 children, comprising all hospital births in the Christchurch region (South Island of New Zealand) between 15 April 1977 and 5 August 1977. ${ }^{16}{ }^{28}$ Information regarding injury events of any kind was gathered from parents during annual interviews and any hospital event verified through medical records.

All the children in the cohort were assigned to one of three groups, two mild head injury groups and a reference control group. No case included in the reference group had any documented evidence of a head injury (no other exclusions, including any other non-neurological injury events). The reference group sample size varied from 613 to 807 cases, depending on variables and missing data. Children included in either mild head injury group had a reported head injury between the ages of 0 to 10 for which medical attention was received and a clear diagnosis of concussion or suspected concussion was given. Mild head injury was further defined by: (1) Loss of consciousness if evident of less than 20 minutes, (2) Hospitalisation of equal to or less than two days, if this occurred, and (3) No evidence of skull fracture. Children were required to meet all criteria for inclusion in the study. Non-specific head injury itself was insufficient for inclusion in the mild head injury groups and any evidence of more severe head injury was an exclusion criterion. One child with a mild head injury was excluded because of severe developmental delays, leaving 132 children eligible for inclusion in the mild head injury group, about $14.5 \%$ of the sample on whom measures were available.

A key factor in this study was that mild head injury cases were divided into two groups, inpatient and outpatient, which is presumed to reflect the initial severity of their injury. The main analyses compared the inpatient and outpatient groups of children who had head injury between the ages of 0 and 10 with the reference group. Thirty six children had been admitted to hospital for less than two days as a result of any mild head injury event before age 10 (inpatient group). Ninety six children experienced a mild head injury before age 10, but were seen by a general practitioner or an accident and emergency department and sent home (outpatient group). In the 20 cases where multiple head injuries were sustained between ages $0-10$, the most severe injury was used to assign group (seven inpatient group cases). Children who had experienced a mild head injury were also divided according to the age at which the injury occurred but excluded from the $0-5$ year injury group if they had any documented head injury between ages 6-10 years and excluded from the 6-10 year injury group if they had any documented head injury between ages $0-5$. One hundred and one mild head injury events were reported between the ages of 0 and 5, of which $51 \%$ were in boys. Fifty three injury events occurred from 6-10 years of which $70 \%$ were in boys. Children who required inpatient care were more likely to be male, making up $72 \%, 66 \%$, and $92 \%$ of children in the inpatient $0-10,0-5$, and 6-10 year groups, respectively. Injury resulted from an acceleration/deceleration event in all cases that required inpatient care, with $78 \%$ (28 of 36 ) being the result of falls, $8.3 \%$ ( 3 of 36 ) hit by an object, $5.6 \%$ ( 2 of 36 ) as a passenger in a vehicle, and $2.8 \%$ ( 1 of 36 ) from a collision with a stationary object (no details were recorded in two cases).

\section{Procedure}

Information on the children regarding both pre-injury and post-injury functioning was collected throughout the course of the study from a wide range of sources, including parental interview, teacher report, standardised testing, and medical records. These observations provided data on a wide range of child and family variables to control for potential confounding factors (see table 1). Details for the measures used in this study have been published elsewhere. ${ }^{15} 16^{28-31}$

\section{Psychosocial outcomes}

A combined version of the Rutter and Connors maternal report questionnaires was used to obtain yearly ratings from mothers regarding hyperactivity/inattention and conduct disordered behaviour and a parallel version was used by the child's teachers to assess these behaviours at school (each measure was averaged for years 10 to 13 inclusive). Items were selected from the original questionnaires to conform to the DSM-III criteria. The resulting scales have been found to have good reliability with coefficient $\alpha$ values ranging from 0.82 to 0.93 .

\section{Academic/cognitive outcomes}

Global cognitive functioning was assessed at 8 years of age using the WISC-R, so this measure could only be used to compare the reference group with the mild head injury groups who had sustained their injury before age 5 . The Burt Word Reading Test (reliability of 0.98), which consists of a list of 110 words graded in order of difficulty is designed to provide a broad measure of early word reading skills among children, and was administered annually from age 8 . Language was also assessed using the Progressive Achievement Test (PAT) of reading comprehension (reliability of 0.83 ), administered to the children when they were 10 years of age and again at 12 years of age. The PAT of mathematics (reliability of 0.87 ) was used when the children were 11 years of age. Lastly, performance on national examinations (School Certificate) was used to assess general academic achievement at the age of 15 or 16 . 
Table 1 Family and individual characteristics of the reference group, outpatient and inpatient mild head injury groups

\begin{tabular}{|c|c|c|c|c|}
\hline Variable & Reference & Outpatient & Inpatient & p Level \\
\hline Family adverse life events per year, $1-5$ y & $2.02(1.30)$ & $2.29(1.30)$ & $2.73(1.40)$ & $<0.00^{*}$ \\
\hline Family adverse life fe events per year, $6-10$ y & $2.51(1.60)$ & $3.00(1.80)$ & $3.33(1.30)$ & $<0.00^{*}$ \\
\hline Mothers age $\dagger$ & $26.0(5.00)$ & $25.4(4.70)$ & $24.9(4.80)$ & $>0.25^{*}$ \\
\hline Birth weight $(\mathrm{kg})$ & $3.36(0.53)$ & $3.39(0.53)$ & $3.28(0.54)$ & $>0.55^{*}$ \\
\hline \multicolumn{5}{|c|}{ Mother's positive emotional responses to child, age $3 \ddagger$} \\
\hline mean & $8.14(1.70)$ & $8.47(1.40)$ & $7.89(2.00)$ & $>0.10^{*}$ \\
\hline median & 9.00 & 9.00 & 8.00 & $>0.10$ \\
\hline \multicolumn{5}{|l|}{ Mother's punitive responses to child age $3 \ddagger$} \\
\hline mean & $0.84(0.80)$ & $1.10(0.96)$ & $1.03(1.10)$ & $<0.01$ * \\
\hline median & 1.00 & 1.00 & 1.00 & $<0.03$ \\
\hline Step parent changes, $0-5$ y & $7.3 \%$ & $8.3 \%$ & $13.9 \%$ & $>0.25$ \\
\hline Step parent changes, $6-10 y$ & $7.1 \%$ & $13.5 \%$ & $5.6 \%$ & $<0.07^{*}$ \\
\hline Parental separations, $0-5$ y & $12.7 \%$ & $14.6 \%$ & $16.7 \%$ & $>0.60$ \\
\hline Parental separations, $6-10 y$ & $13.0 \%$ & $17.7 \%$ & $33.3 \%$ & $<0.00^{*}$ \\
\hline Parental reconciliations, $0-5$ y & $4.9 \%$ & $5.2 \%$ & $11.1 \%$ & $>0.25$ \\
\hline Parental reconciliations, $6-10$ y & $5.4 \%$ & $6.2 \%$ & $8.3 \%$ & $>0.70$ \\
\hline \multicolumn{5}{|l|}{ Mothers education $\dagger$} \\
\hline No formal & $49.7 \%$ & $56.2 \%$ & $55.6 \%$ & $>0.20 *$ \\
\hline Secondary & $30.2 \%$ & $28.1 \%$ & $36.1 \%$ & \\
\hline Tertiary & $20.0 \%$ & $15.6 \%$ & $8.3 \%$ & \\
\hline Difficult to manage, $2-5$ y§ & $41.2 \%$ & $52.2 \%$ & $60.6 \%$ & $<0.02 *$ \\
\hline Aggressive, $2-5$ y§ & $33.3 \%$ & $46.7 \%$ & $39.4 \%$ & $<0.06^{*}$ \\
\hline \multicolumn{5}{|l|}{ SES of family $\dagger$} \\
\hline Semi-skilled & $26.9 \%$ & $19.8 \%$ & $16.7 \%$ & $>0.20 *$ \\
\hline Skilled & $52.6 \%$ & $55.2 \%$ & $66.7 \%$ & \\
\hline Professional & $20.5 \%$ & $25.0 \%$ & $16.7 \%$ & \\
\hline \multicolumn{5}{|l|}{ Number of parents $\dagger$} \\
\hline Single parent & $6.9 \%$ & $8.3 \%$ & $11.1 \%$ & $>0.55$ \\
\hline Two parent & $93.1 \%$ & $91.7 \%$ & $88.9 \%$ & \\
\hline \multicolumn{5}{|l|}{ Birth order } \\
\hline First & $38.3 \%$ & $35.4 \%$ & $38.9 \%$ & $>0.65$ \\
\hline Second & $35.3 \%$ & $45.8 \%$ & $22.2 \%$ & \\
\hline Third & $18.3 \%$ & $15.6 \%$ & $30.6 \%$ & \\
\hline Fourth & $5.5 \%$ & $0.0 \%$ & $5.6 \%$ & \\
\hline Fifth & $2.6 \%$ & $3.1 \%$ & $2.8 \%$ & \\
\hline Global family living standard, $0-10$ y & $28.6(4.62)$ & $28.5(5.10)$ & $29.2(4.56)$ & $>0.60$ \\
\hline
\end{tabular}

\section{RESULTS}

\section{Design and statistical analyses}

Outcomes were treated as continuously scored variables and subjected to analysis of variance using three head injury status groups (reference, outpatient, inpatient) and then to analysis of covariance using 12 child and family measures as covariates (see table 1). The main analyses examined the effects of mild head injury before age 10, followed by separate analyses for two developmental periods, injury before age 5 exclusively (0-5 years) and injury after age 5 exclusively (6-10 years). There were no significant group by gender interactions. Sample sizes varied as a function of missing data on any outcome variable or covariate. While some children in the inpatient group had experienced multiple injuries (7 of 36), the actual number of cases used in the final analysis never exceeded 4 of 28 (other than the outcome variable, information on all 12 covariates was also required for any analysis). Multiple injury did not affect the inpatient $0-10$ year results reported here because the behavioural ratings of two of these children were in the lower range of scores for their group, one was in the middle range and one was in the upper range. Only two multiple injury cases were included in the inpatient $0-5$ year subgroup (one case with psychosocial scores in the lower range and one in the upper range). In the inpatient 6-10 year subgroup, no cases of multiple injury within this age occurred and injury before age 5 was an exclusion criterion.

\section{Potential confounding factors}

Child and family characteristics were analysed across the three head injury status groups using one way analysis of variance or Kruskal-Wallis tests as appropriate (table 1). For some variables, information was available on a yearly basis, so it was first averaged over the course of the two developmental periods of interest, $0-5$ years and $6-10$ years. For descriptive purposes, many of these variables are expressed as proportions, rather than means or medians. To ensure a conservative analysis on these measures for the later ancovas, a lenient significance criterion $(\mathrm{p}<0.10)$ for head injury status was adopted for the selection of appropriate covariates. Eight of the variables listed in table 1 showed at least this degree of association with head injury status on one or more of the analyses conducted on the $0-10,0-5$, and/or 6-10 year groups. To control for at least some aspects of other unidentified factors or potential confounds, four birth related variables were also added to the covariate list (birth weight; mother's age; mother's educational level; socioeconomic status of family). Using these covariates, adjusted mean values were generated for each outcome variable, which may be interpreted as the hypothetical value when the effects of family and individual factors have been taken into account.

\section{Hyperactivity/inattention and head injury status (0-10 years)}

The left half of table 2 provides the unadjusted mean ratings of hyperactivity/inattention, averaged over years 10-13, for the reference (no injury) group and the outpatient and inpatient groups of children injured between 0-10 years of age. There was clear evidence of different mean scores for hyperactivity/ inattention, in terms of mother ratings, teacher ratings, and the combined score (respectively, $F(2,912)=7.70, \mathrm{p}<0.001 ; F$ $(2,890)=8.08, \mathrm{p}<0.001 ; F(2,890)=8.31, \mathrm{p}<0.001)$. Post hoc 


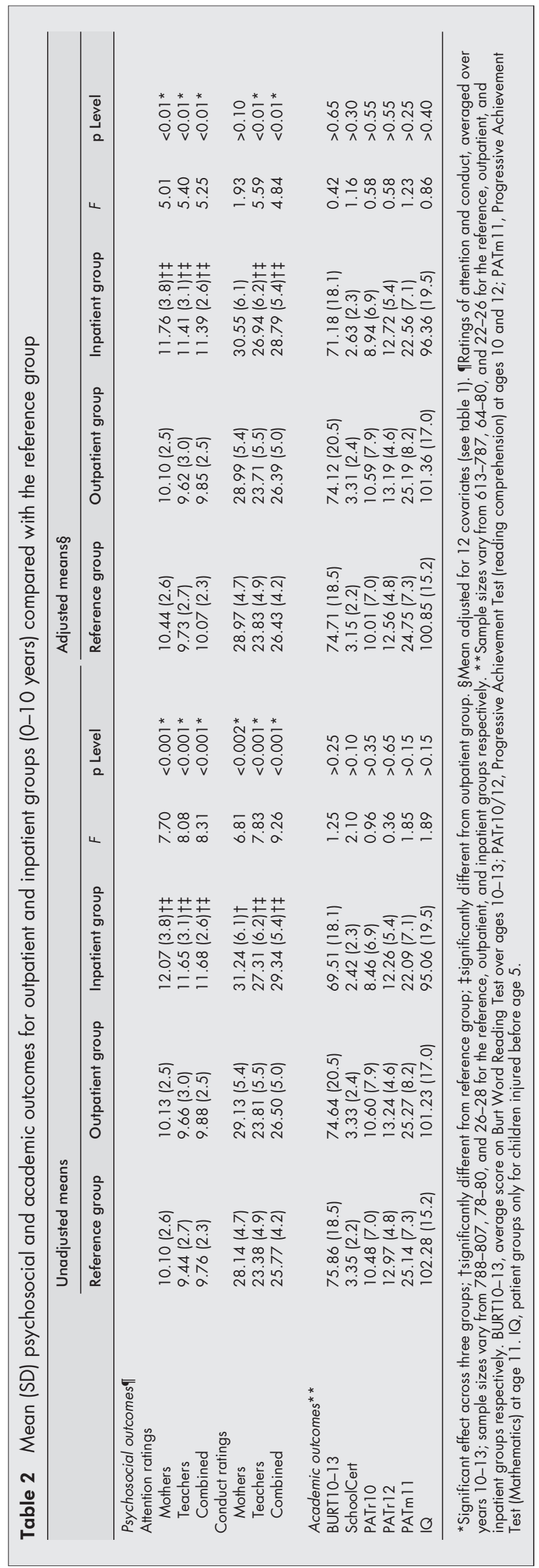

Scheffé tests confirmed that all three of these (unadjusted) mean ratings for children in the inpatient $0-10$ year group were higher than those of both the reference group (all $\mathrm{p}<0.001$ ) and the outpatient $0-10$ year group (all $\mathrm{p}<0.004$ ), whereas the outpatient and reference groups had equivalent mean scores. Note, the reference and outpatient groups' mean scores for mother and teacher ratings were close to the minimum possible ( 8 and 7 , respectively).

The adjusted mean ratings of hyperactivity/inattention are shown on the right half of table 2, after controlling for 12 potential confounds. The mean ratings for the reference group increased slightly and those for the inpatient $0-10$ year group decreased slightly. None the less, the analyses of covariance reproduced a reliable group main effect for head injury status for mother, teacher and combined ratings (respectively, $F(2$, $900)=5.01, \mathrm{p}<0.01 ; F(2,878)=5.40, \mathrm{p}<0.01 ; F(2,878)$ $=5.25, \mathrm{p}<0.01)$. Again, pairwise Scheffé comparisons confirmed that the mean ratings for children in the inpatient $0-10$ year group were higher than those of both the reference (all $\mathrm{p}<0.001$ ) and outpatient groups (all $\mathrm{p}<0.003)$, whereas the latter two groups were equivalent.

\section{Conduct and head injury status ( $0-10$ years)}

Unadjusted mean ratings of conduct, averaged over years $10-13$ for children injured between $0-10$ years of age, are shown on the left half of table 2 . All three measures of conduct ratings also produced significant group main effects for head injury status (mother, $F(2,912)=6.81, \mathrm{p}<0.002$; teacher, $F(2$, $890)=7.83, \mathrm{p}<0.001$; combined ratings, $F(2,890)=9.26$, $\mathrm{p}<0.001)$. Post hoc analyses confirmed that ratings for all three measures of conduct were higher in the inpatient $0-10$ year group than those of the reference group $(\mathrm{p}<0.01)$, as was the case when the inpatient 0-10 year group was compared with the outpatient $0-10$ year group for teacher and combined ratings $(\mathrm{p}<0.02)$ but not mother ratings $(\mathrm{p}<0.14)$. As with the hyperactivity/inattention measure, the outpatient $0-10$ year group and reference group had comparable mean conduct ratings. Note, the latter groups' mean scores for mother and teacher ratings were close to the minimum possible (23 and 20 , respectively).

Adjusted mean ratings of conduct averaged over 10-13 years of age are shown on the right half of table 2. Analyses of covariance confirmed that a significant group main effect for head injury status remained evident for teacher ratings of conduct, $F(2,878)=5.59, \mathrm{p}<0.01$ and combined ratings, $F(2$, $878)=4.84, \mathrm{p}<0.01$, but not for mother ratings, $F(2,900)$ $=1.93, \mathrm{p}<0.15$, the latter being similar across the three groups. Post hoc analyses confirmed that teacher and combined ratings were higher for the inpatient $0-10$ year group than those of the reference group $(p<0.001)$ and the outpatient group $(\mathrm{p}<0.004)$.

\section{Psychosocial measures: effect sizes and developmental subgroups}

Table 3 expresses the standardised mean differences for the behavioural ratings between the inpatient groups and the reference group (that is, Cohen's d, after adjustment for sample sizes; D-Stat programme ${ }^{32}$ ). Robust estimates of group differences are evident when the $95 \%$ confidence intervals for d do not include the zero value. The outpatient mild head injury groups were comparable to the reference group, irrespective of the age at injury, so those effect sizes are not provided. Note that the data provided in table 3 also summarise the effects of age at injury, based on injury occurring exclusively in the two developmental periods, $0-5$ years and $6-10$ years. The inpatient effect sizes for the cognitive/academic measures were generally small and unreliable (for unadjusted means, average $d=0.32,95 \% \mathrm{CI}=-0.22$ to 0.86 ; for adjusted means, average $\mathrm{d}=0.20,95 \% \mathrm{CI}=-0.38$ to 0.71 ), with the exception of the Burt Word Reading difference in the 6-10 year inpatients $(\mathrm{d}=0.95,95 \% \mathrm{CI}=0.07$ to 1.83$)$. 
Table 3 Inpatient compared with reference group: effect sizes for psychosocial outcomes at age 10-13

\begin{tabular}{|c|c|c|c|c|c|c|c|c|}
\hline & \multirow[b]{2}{*}{ Age at injury } & \multirow{2}{*}{$\begin{array}{l}\text { Reference/ } \\
\text { inpatient sample } \\
\text { size }\end{array}$} & \multicolumn{3}{|c|}{ Unadjusted means } & \multicolumn{3}{|c|}{ Adjusted means } \\
\hline & & & Cohen's d & $95 \% \mathrm{Cl}(\mathrm{d})$ & $r$ & Cohen's d & $95 \% \mathrm{Cl}(\mathrm{d})$ & $r$ \\
\hline \multicolumn{9}{|c|}{ Attention ratings } \\
\hline \multirow[t]{3}{*}{ Mother } & $0-10$ & $807 / 28$ & 0.74 & 0.37 to 1.12 & 0.35 & 0.50 & 0.12 to 0.88 & 0.24 \\
\hline & $6-10$ & 9 & 0.70 & 0.04 to 1.36 & 0.33 & 0.37 & -0.29 to 1.02 & 0.18 \\
\hline & $0-5$ & 17 & 0.91 & 0.42 to 1.39 & 0.41 & 0.62 & 0.14 to 1.01 & 0.30 \\
\hline \multirow[t]{3}{*}{ Teacher } & $0-10$ & $788 / 26$ & 0.81 & 0.42 to 1.21 & 0.38 & 0.62 & 0.23 to 1.01 & 0.30 \\
\hline & $6-10$ & 8 & 1.14 & 0.45 to 1.84 & 0.50 & 0.89 & 0.19 to 1.58 & 0.41 \\
\hline & $0-5$ & 16 & 0.79 & 0.29 to 1.29 & 0.37 & 0.58 & 0.09 to 1.08 & 0.28 \\
\hline \multirow[t]{3}{*}{ Combined } & $0-10$ & $788 / 26$ & 0.83 & 0.44 to 1.22 & 0.38 & 0.57 & 0.18 to 0.96 & 0.24 \\
\hline & $6-10$ & 8 & 1.06 & 0.36 to 1.76 & 0.47 & 0.70 & 0.01 to 1.40 & 0.33 \\
\hline & $0-5$ & 16 & 0.86 & 0.37 to 1.36 & 0.40 & 0.58 & 0.09 to 1.08 & 0.28 \\
\hline \multicolumn{9}{|c|}{ Conduct ratings } \\
\hline \multirow[t]{3}{*}{ Mother } & $0-10$ & $807 / 28$ & 0.65 & 0.27 to 1.03 & 0.31 & 0.33 & -0.05 to 0.71 & 0.16 \\
\hline & $6-10$ & 9 & 0.58 & -0.08 to 1.12 & 0.28 & 0.14 & -0.52 to 0.80 & 0.07 \\
\hline & $0-5$ & 17 & 0.80 & 0.32 to 1.28 & 0.37 & 0.39 & 0.09 to 0.87 & 0.19 \\
\hline \multirow[t]{3}{*}{ Teacher } & $0-10$ & $789 / 26$ & 0.79 & 0.40 to 1.18 & 0.37 & 0.63 & 0.24 to 1.02 & 0.30 \\
\hline & $6-10$ & 8 & 0.67 & -0.03 to 1.36 & 0.32 & 0.42 & -0.29 to 1.12 & 0.20 \\
\hline & $0-5$ & 16 & 0.99 & 0.50 to 1.49 & 0.45 & 0.81 & 0.32 to 1.31 & 0.38 \\
\hline \multirow[t]{3}{*}{ Combined } & $0-10$ & $789 / 26$ & 0.84 & 0.45 to 1.23 & 0.39 & 0.56 & 0.16 to 0.95 & 0.27 \\
\hline & $6-10$ & 8 & 0.74 & 0.05 to 1.44 & 0.35 & 0.33 & -0.37 to 1.02 & 0.16 \\
\hline & $0-5$ & 16 & 1.03 & 0.54 to 1.53 & 0.46 & 0.73 & 0.23 to 1.22 & 0.34 \\
\hline
\end{tabular}

Using Cohen's ${ }^{33}$ conventions $(\mathrm{d}=0.5$ for a medium effect size and 0.8 for a large effect size), it is clear that mild head injury requiring brief hospitalisation at some point during years $0-10$ of age was generally associated with large effect sizes on behavioural ratings of hyperactivity/inattention (left half of table 3). When the means were adjusted for 12 covariates the differences remained for hyperactivity/inattention, but were mostly reduced to medium range effect sizes (right half of table 3). An exception was the small effect size for adjusted mother ratings for the inpatient 6-10 year group, which contrasts with the more reliable effect for teacher ratings in this group. The effect sizes for conduct ratings were also large, but tended to be both weaker and less reliable when the first injury occurred after age five (compare effect sizes and confidence intervals for age $0-5$ versus age $6-10$, left half of table 3). This neurodevelopmental difference between the effects of injury before or after age 5 is more readily apparent for the adjusted mean values of conduct ratings. In this latter instance, injury before age 5 produced reliable medium to large effects, unlike the effects of injury after age 5 (right half of table 3 ).

This evidence that some differences are related to the age at injury was supported by post hoc Scheffé tests on the adjusted mean behavioural ratings for the inpatient $0-5$ year group and the inpatient 6-10 year group. Post hoc tests on these adjusted measures confirmed significant differences between the inpatient $0-5$ year group and the reference group in terms of mother $(p<0.001)$, teacher $(p<0.01)$, and combined $(p<0.01)$ hyperactivity/inattention ratings, and on mother, teacher, and combined conduct ratings (all $\mathrm{p}<0.001$ ). Teacher and combined ratings of hyperactivity/inattention were also significantly different in the inpatient $6-10$ year group $(\mathrm{p}<0.05)$. However, neither the mother ratings of hyperactivity/ inattention $(\mathrm{p}<0.07)$ nor any conduct ratings reached significance (mother, $\mathrm{p}<0.15$; teacher, $\mathrm{p}<0.15$; combined, $\mathrm{p}<0.06$ ).

\section{Cognitive/academic outcomes}

Although the inpatient group tended to score more poorly on the cognitive and academic measures, no significant group or pair wise effects were identified (table 2). Analyses based on head injury before or after age 5 also produced no effects, with the exception of poorer Burt Word Reading scores for the inpatient 6-10 year group. This finding is tempered by the fact that relatively few children overall took this test (the inpatient sample was only five cases). There was no significant group main effect for IQ scores at age 8, which was used to compare children injured before age 5 with those in the reference group.

\section{DISCUSSION}

This study showed that children who experienced a mild head injury of sufficient severity to warrant temporary hospitalisation between the ages of $0-10$ years were likely to show adverse psychosocial outcomes in terms of hyperactivity/ inattention and conduct disordered behaviour at 10-13 years of age, especially if the injury occurred before age 5 . These effects persisted after statistical control of a wide range of potential confounds. By contrast, children in the outpatient mild head injury group were comparable to the non-injured reference group on these psychosocial measures. Regardless of injury severity, mild head injury did not markedly affect general intelligence or academic skills. Adverse psychosocial outcome after mild head injury in children has been reported previously, ${ }^{202233^{34-36}}$ but not by all studies. ${ }^{37-41}$ The inconsistent evidence on the effects of mild head injury in children is hampered by methodological limitations, with few studies meeting even four of Satz's recommendations. ${ }^{45}$ The current findings, then, must also be considered in the context of the study's strengths and limitations.

The Christchurch Health and Development Study has used a longitudinal epidemiological approach. Its unique characteristics incorporate many methodological advantages and make it probable that its findings have wide generalisability. Assessments were made by multiple informants across multiple situations and the data were free of any injury related bias. Also, a large unselected reference group was used that was identical in age to the head injury groups and highly comparable in terms of general education, history, and social circumstances. The focus on the effects of early head injury and a longitudinal perspective represent two important features of 
this study. Childhood is obviously characterised by rapid developmental change, yet the long term consequences of early injuries have seldom been investigated previously. ${ }^{36}{ }^{42}$ Indeed, only a handful of studies have examined outcomes for children of any age more than five years after injury. ${ }^{26} 43-46$

Some of the previous research suffered from the problem of poor definition of mild head injury. Often, cases with more severe head injuries have been included in the mild injury group or there has been a lack of minimum inclusion criteria. ${ }^{2-4}$ Mild head injury in our study was restricted to cases with a documented diagnosis of concussion/strongly suspected concussion, and loss of consciousness if present for not more than 20 minutes, which are accepted criteria in the contemporary literature. ${ }^{27}$ The Glasgow Coma Score ${ }^{3}{ }^{47}$ and posttraumatic amnesia were not in common use when the cohort's injuries were recorded, but these measures are in any case problematic with children. ${ }^{3}$ Instead, injury severity within the mild domain was examined by categorising cases into those requiring either inpatient or outpatient care. This division produced the important finding that there is both a level of mild injury for which there are adverse outcomes and a lower level of mild head injury for which there is likely to be no detectable deficit. The adverse psychosocial findings reported here would not have emerged had the children with mild head injury been treated as a homogeneous group. Only one other study has investigated this issue, but it concluded that an inpatient/outpatient dimension was irrelevant because this factor was inconsistent across various measures used. ${ }^{20}$ No relevant details were reported in that study, but one difference was that no cases of injury before age 5 were included. In any case, it is perhaps unreasonable to expect diverse measures to reflect consistent differences after mild head injury.

A lack of control groups in much of the research to date is another reason why it has been difficult to determine whether psychosocial outcomes can be attributed to mild head injury. The use of an "other injury" group is even advocated," although it has been questioned whether injury controls such as burns, lacerations, or fractures are appropriate because they differ in terms of visibility and pain associated with the trauma. ${ }^{2}$ In this study, the division of cases according to severity level meant that the outpatient group effectively provided an excellent and appropriate injury control for the inpatient group. Indeed, the outpatient group was similar to the inpatient group in terms of the general nature of trauma, and both the outpatient group and the reference group were ideally suited controls in terms of age, educational experience, and general social background. If non-specific factors are responsible for the differences in children seeking medical attention, then our two head injury groups should have been comparable and similarly different to the non-injured reference group. In contrast, the attention and conduct measures used here revealed that the children in the outpatient group differed from the inpatient group, but were indistinguishable from the reference group.

One issue that drives the question of appropriate controls is the concern that any behaviour associated with mild head injury simply reflects existing characteristics in the child or their family that predispose these children to injury. ${ }^{45} 48$ This view has also been challenged. Not surprisingly, there is conflicting evidence whether children with mild head injury are already problem children or that their families are problem families. ${ }^{3-5}{ }^{49-51}$ In addition to control groups, statistical or methodological control of these characteristics indicates whether any differences are specifically related to a mild head injury. ${ }^{48}$ Previous research has relied on observations or an informant's memory after an injury event. ${ }^{39}{ }^{52-54}$ By contrast, this study is only the second to our knowledge that has used prospectively collected data on both the child and family. ${ }^{20}$ Although there were differences between our three comparison groups in terms of some child and family characteristics (table 1), the size and direction of these differences did not consistently map on to the observed psychosocial differences. The outpatient and reference group showed virtually identical psychosocial scores, but the outpatient group was intermediate to the reference and inpatient groups on some child and family measures (adverse early life events, difficulty to manage, parental separation for age 6-10 years) and relatively less favourable than the other two groups on other measures (aggression, step-parent changes for age 6-10 years). More importantly, our main outcomes were reliable both before and after being adjusted for these and a wide range of other possible confounding factors. These considerations make it unlikely that the negative psychosocial outcomes we observed were attributable to any non-specific effects of the trauma or unforeseen child and family confounds.

An important question regarding the effects of mild head injury in children is whether they are at best small, temporary, and trivial. ${ }^{45}$ In addition to including a high proportion of cases at the milder end of the injury continuum, studies have often used the Child Behaviour Check List, ${ }^{38} 404155$ a screening device that uses a clinical threshold to detect psychopathology. The measurement of hyperactivity/inattention or conduct disorder based on the Rutter and Conners rating scales ${ }^{3056}$ is more likely to detect the subtle changes that might be expected after mild head injury. ${ }^{57-59}$ Whereas the majority of children in our reference and outpatient groups showed only one symptom (that is, close to the minimum rating possible), the inpatient group showed a mean increase equivalent to an additional two to three problem behaviours. In addition, the inpatient $0-10$ year group showed generally large effect sizes for both hyperactivity/inattention and conduct ratings and all but one of these measures remained in the medium to large range even after covariate adjustment. When analysed according to age, consistently more reliable and often larger changes in these measures were associated with injury before age 5 . This evidence suggests that mild head injury can result in significant outcomes for some children. Moreover, these effects were long term, being evident 8-13 years after the inpatient injury in the case of the $0-5$ year group.

Our sample of up to 132 injury cases far exceeds the recommendation of 20 suggested by Satz. ${ }^{4}$ Clearly, there was an ample sample for the various outpatient head injury analyses, but one limitation is the variation in the number of children available for some of the head injury inpatient subgroups. There were 26 to 28 inpatient cases with sufficient data available for the $0-10$ year analyses of the psychosocial ratings, but only 16 or 17 inpatient cases for the $0-5$ year analyses. A more serious problem was that our evidence on the effects of later injury, after age 5 , is limited by the relatively few cases in the inpatient 6-10 year subgroup ( 8 or 9 for psychosocial ratings; less for the academic outcomes), but it suggests that relatively fewer effects are apparent in this instance. For this older group, only the effects of mild head injury on teacher ratings of hyperactivity/inattention, but not mother ratings of hyperactivity/inattention or teacher and mother conduct ratings, remained significant after child and family confounds were taken into account. Similarly, previous evidence on older children who experience a mild head injury has found that increases in conduct measures, rather than hyperactivity/inattention measures, may reflect other confounds, ${ }^{35}{ }^{60}$ and that increased teacher ratings of hyperactivity/ inattention remain after statistical control for non-specific confounds. ${ }^{20}$

These findings show that mild head injury in children is not always a completely benign event. Our evidence provides strong support for the suggestion made by Asarnow and colleagues ${ }^{48}$ that there is a level of mild head injury for which no discernible long term deficits will be evident. Conversely, it seems that more severe mild head injuries can have some clear adverse outcomes, at least in terms of psychosocial behaviour. Unfortunately, we had insufficient information to determine any specific clinical differences between our inpatient and 
outpatient groups. Hospital admission criteria differ over time and between different centres, so it is unlikely that temporary hospitalisation compared with outpatient care will provide a universally useful predictor of potential outcome. The task facing the medical community is to find more objective ways at the time of injury of identifying those children who are vulnerable to adverse early life outcomes and to identify the nature of the injury that might predict such outcomes. The use of sensitive brain imaging techniques is increasingly suggested as essential for the detection of individuals with mild head trauma who may have experienced clinically significant brain injury, ${ }^{61-63}$ but the use of these techniques with young children is problematic. An additional approach may emerge from recent findings that an increase in blood markers may be predictive of initial brain injury. ${ }^{64}$ If delayed onset of behavioural impairments and a failure to mature appropriate social and emotional domains is indeed a characteristic of some early injuries, then periodic management and intervention may minimise any potentially deteriorating psychosocial function.

In summary, our findings provide an answer to the conflicting views on the effects of mild head injury in early childhood by showing that in many respects both sides of the debate are correct. That is, the effect of mild head injury depends on whether it is of the more frequent instance that requires no inpatient care as compared with the more severe instance for which some inpatient observation may be warranted. Only the more severe injuries are likely to produce long term negative outcomes, which in turn depends on the particular measure under study, the reliability and sensitivity of the measure (for example, aggregated over time compared with a single point estimate), and probably to some degree on whether the injury occurs before age 5 .

\section{ACKNOWLEDGEMENTS}

The Christchurch Health and Development Study has been funded by grants from the Health Research Council of New Zealand, the National Child Health Research Foundation, the Canterbury Medical Research Foundation and the New Zealand Lottery Grants Board. The authors also thank Dr Paul Barrett for his assistance during the initial stages of this project.

\section{Authors' affiliations}

A McKinlay, J C Dalrymple-Alford, Department of Psychology, University of Canterbury, and Christchurch Movement Disorders and Brain Research Group, Christchurch, New Zealand

L J Horwood, D M Fergusson, Christchurch Health and Development Study, Christchurch Movement Disorders and Brain Research Group, and University of Otago, Dunedin

\section{REFERENCES}

1 Taylor HG, Alden J. Age-related differences in outcomes following childhood brain insults: An introduction and overview. Journal of the International Neuropsychological Society 1997;3:555-67.

2 Beers SR. Cognitive effects of mild head injury in children and adolescents. Neuropsychol Rev 1992;3:281-320.

3 Gronwall D, Wrightson P, McGinn V. Effect of mild head injury during the preschool years. Journal of the International Neuropsychological Society 1997; 3:592-7

4 Satz P, Zaucha K, McCleary C, et al. Mild head injury in children and adolescents: a review of studies (1970-1995). Psychol Bull 1997; 122:107-31

5 Satz P. Mild head injury in children and adolescents. Current Directions in Psychological Science 2001;10:106-9.

6 Levin HS, Williams DH, Eisenberg HM, et al. Serial MRI and neurobehavioural findings after mild to moderate closed head injury. $J$ Neurol Neurosurg Psychiatry 1992;55: 255-62.

7 Mittl RL, Gossman RI, Hiehle JF, et al. Prevalence of MR evidence of diffuse axonal injury in patients with mild head injury and normal head CT findings. American Journal of Neuroradiology 1994;15:1583-9.

8 Kant R, Smith-Seemiller L, Isaac G, et al. Tc-HMPAO SPECT in persistent post-concussion syndrome after mild head injury: comparison with MRI/CT. Brain Inj 1997;1 1:115-24.

9 Voller B, Benke T, Benedetto K, et al. Neuropsychological, MRI and EEG findings after very mild traumatic brain injury. Brain Inj $1999 ; 13: 821-87$.
10 Hart K Faust D. Prediction of the effects of mild head injury: a message about the Kennard Principle. J Clin Psychol 1988;44:780-2.

11 Webb C, Rose FD, Johnson DA, et al. Age and recovery from brain injury: clinical opinions and experimental evidence. Brain Inj 1996; 10:303-10.

12 Anderson VA, Morse SA, Klug G, et al. Predicting recovery from head injury in young children: a prospective analysis. Journal of the International Neuropsychological Society 1997;3:568-580.

13 Kraus JF, Fife D, Conroy C. Pediatric brain injuries: the nature, clinical course and early outcomes in a defined United States' population. Pediatrics 1987;79:501-7.

14 Guerrero JL, Thurman DJ, Sniezek JE. Emergency department visits associated with traumatic brain injury: United States, 1995-1996. Brain Inj 2000;14:181-6.

15 Fergusson DM, Horwood L, Lloyd M. Confirmatory factor models of attention deficit and conduct disorder. J Child Psychol Psychiatry $1991 ; 32: 257-74$

16 Fergusson DM, Lynskey MT. Conduct problems in childhood and psychosocial outcomes in young adulthood: a prospective study. Journal of Emotional and Behavioural Disorders 1998;6:2-18.

17 Chadwick O, Rutter M, Brown G, et al. A prospective study of children with head injuries: Il. cognitive sequelae. Psychol Med 1981;11:49-61.

18 Oddy M. Head injury during childhood. Neuropsychological Rehabilitation 1993;3: 301-20.

19 Eslinger PJ, Biddle KR, Grattan LM. Cognitive and social development in children with prefrontal cortex lesions. In: Krasnegor NA, Lyon GR, Goldman-Rakic PS, eds. Development of the prefrontal cortex: evolution, neurobiology, and behavior. Baltimore: Brookes, 1997:295-335.

20 Bijur PE, Haslum M, Golding J. Cognitive and behavioral sequelae of mild head injury in children. Pediatrics 1990;86:337-44.

21 Bijur PE, Haslum M, Golding J. Cognitive outcomes in multiple mild head injuries in children. Developmental and Behavioral Pediatrics 1996;17:143-8.

22 Casey R, Ludwig S, McCormick MC. Morbidity following minor head trauma in children. Pediatrics 1986;78:497-502.

23 Black $\mathbf{P}$, Blumer D, Wellner AM, et al. The head-injured child: time-course of recovery, with implications for rehabilitation. In: Head injuries proceedings of an International Symposium held in Edinburgh and Madrid, 2-10 April 1970. Edinburgh: Churchill Livingstone, 1971:131-7.

24 Klonoff $\mathbf{H}$, Low MD, Clark C. Head injuries in children: a prospective five year follow-up. Journal Neurol Neurosurg Psychiatry 1977;40:1211-19

25 Tompkins CA, Hollang AL, Ratcliff G, et al. Predicting cognitive recovery from closed head-injury in children and adolescents. Brain Cogn 1990;13:86-97.

26 Klonoff $\mathbf{H}$, Clark C, Klonoff PD. Long-term outcome of head injuries: a 23 year follow up study of children with head injuries. J Neurol Neurosurg Psychiatry 1993;56:410-15.

27 Kibby MY, Long CJ. Minor head injury: attempts at clarifying the confusion. Brain Inj 1996:10:159-86.

28 Fergusson DM, Horwood LJ. The effects of lead levels on the growth of word recognition in middle childhood. Int J Epidemiol 1993;22:891-7.

29 Fergusson DM, Horwood L, Lynskey MT. Prevalence and comorbidity of DSM-III-R diagnoses in a birth cohort of 15 year olds. J Am Acad Child Adolesc Psychiatry 1993;32: 1127-34.

30 Fergusson DM, Lynskey MT, Horwood L. Attentional difficulties in middle childhood and psychosocial outcomes in young adulthood. $J$ Child Psychol Psychiatry 1997;38:633-44.

31 Fergusson DM, Horwood L, Shannon FT. Family ethnic composition, socioeconomic factors and childhood disadvantage. New Zealand Journal of Educational Studies 1982;17: 171-9.

32 Johnson BT. DStat 1.10 Upgrade: Software for the meta-analytic review of research literatures. Hillsdale, NJ: Lawrence Erlbaum Associates, 1993.

33 Cohen J. Statistical power analysis for the behavioral sciences. Hillsdale, NJ: Erlbaum, 1988

34 Asarnow RF, Satz P, Light R, et al. Behaviour problems and adaptive functioning in children with mild and severe closed head injury. J Pediatr Psychol 1991;16:543-55.

35 Max JE, Lindgren SD, Knutson C, et al. Child and adolescent traumatic brain injury: correlates of disruptive behaviour disorders. Brain Inj 1998; 12:41-52.

36 Andrews TK, Rose FD, Johnson DA. Social and behavioural effects of traumatic brain injury in children. Brain Ini 1998;12:133-8.

37 Brown G, Chadwick O, Shaffer D, et al. A prospective study of children with head injuries: III psychiatric sequelae. Psychol Med $1981 ; 11: 63-78$

38 Fletcher JM, Ewing-Cobbs L, Miner ME, et al. Behavioral changes after closed head injury in children. J Consult Clin Psychol 1990;58:93-8.

39 Knights RM, Ivan LP, Ventureyra EC, et al. The effects of head injury in children on neuropsychological and behavioural functioning. Brain Inj 1991;5:339-51.

40 Prior M, Kinsella G, Sawyer M, et al. Cognitive and psychosocial outcome after head injury in children. Australian Psychologist 1994;29:116-23.

41 Kinsella G, Ong B, Murtagh D, et al. The role of the family for behavioral outcome in children and adolescents following traumatic brain injury. J Consult Clin Psychol 1999;67:1 16-23.

42 Anderson VA, Catroppa C, Rosenfeld J, et al. Recovery of memory function following traumatic brain injury in pre-school children. Brain Inj 2000;14:670-92. 
43 Horowitz I, Costeff H, Sadan N, et al. Childhood head injuries in Israel: epidemiology and outcome. International Rehabilitation Medicine 1983;4:32-6.

44 Costeff $\mathbf{H}$, Abraham E, Brenner T, et al. Late neuropsychologic status after childhood head trauma. Brain Dev 1988;10:371-4.

45 Jordan FM, Cannon A, Murdoch BE. Language abilities of mildly closed head injured (CHI) children 10 years post-injury. Brain In 1992;6:39-44

46 Wrightson P, McGinn V, Gronwall D. Mild head injury in pre-school children: evidence that it can be associated with a persisting cognitive deficit. J Neurol Neurosurg Psychiatry 1995;59:375-80.

47 Teasdale G, Jennett B. Assessment of coma and impaired consciousness: a practical scale. Lancet 1974;ii:81-4.

48 Asarnow RF, Satz P, Light R, et al. The UCLA study of mild closed head injury in children and adolescents In: Broman SH, Michel ME, eds. Traumatic head injury in children New York: Oxford University Press, 1995: 1 17-46.

49 Pelco L, Sawyer M, Duffield G, et al. Premorbid emotional and behavioural adjustment in children with mild head injuries. Brain Inj 1992;6:29-37.

50 Fay GC, Jaffe KM, Polissar NL, et al. Mild pediatric traumatic brain injury: a cohort study. Arch Phys Med Rehabil 1993;74:895-901.

51 Donders J. Premorbid behavioral and psychosocial adjustment of children with traumatic brain injury. J Abnorm Child Psychol 1992;20:233-46.

52 Papero PH, Prigatano GP, Snyder HM, et al. Children's adaptive behavioral competence after head injury. Neuropsychological Rehabilitation 1993;3:321-40

53 Light R, Asarnow R, Satz P, et al. Mild closed-head injury in children and adolescents: Behavior problems and academic outcomes. J Consult Clin Psychol 1998;66:1023-9.
54 Ponsford J, Willmott C, Rothwell A, et al. Cognitive and behavioral outcome following mild traumatic head injury in children. Journal of Head Trauma Rehabilitation 1999:14:360-72.

55 Fletcher JM, Levin HS, Lachar D, et al. Behavioral outcomes after paediatric closed head injury: relationships with age, severity and lesion size. J Child Neurol 1996;11:283-90

56 Fergusson DM, Lynskey MT, Horwood L. Factors associated with continuity and changes in disruptive behavior patterns between childhood and adolescence. J Abnorm Child Psychol 1996;24:533-53.

57 Perrin EC, Stein REK, Drotar D. Cautions in using the child behavior checklist: pbservations based on research about children with a chronic illness.J Pediatr Psychol 1991;16:411-21.

58 Cantwel, DP. Attention deficit disorder: a review of the past 10 years. $J$ Am Acad Child Adolesc Psychiatry 1996;35:978-86.

59 Reitman D, Hummel R, Franz DZ, et al. A review of methods and instruments for assessing externalizing disorders: theoretical and practical considerations in rendering a diagnosis. Clinical Psychology Review considerations in rend

60 Max JE, Robin DA, Lindgren SD, et al. Traumatic brain injury in children and adolescents: psychiatric disorders at two years. J Am Acad Child Adolesc Psychiatry 1997;36: 1278-85

61 Schutzman SA, Barnes P, Duhaime A, et al. Evaluation and management of children younger than two years old with apparently
minor head trauma: proposed guidelines. Pediatrics 2001;107:983-93

62 Stiell IG, Wells GA, Vandemheen K, et al. The Canadian CT head rule for patients with minor head injury. Lancet 2001;357:1391-6.

63 Voller B, Auff E, Schnider P, et al. To do or not to do? Magnetic resonace imaging in mild traumatic brain injury. Brain In 2001;15:107-15.

64 Herrmann M, Curio N, Jost S, et al. Release of biochemical markers of damage to neuronal and glial brain tissue is associated with short and long term neuropsychological outcome after traumatic brain injury. J Neurol Neurosurg Psychiatry 2001;70:95-100. 